\title{
Energy absorption mechanism of open-cell Zr-based bulk metallic glass foam
}

\author{
X. Wei, J.H. Chen and L.H. Dai* \\ State Key Laboratory of Nonlinear Mechanics, Institute of Mechanics, Chinese Academy of Sciences, Beijing 100190, \\ People's Republic of China
}

Received 6 December 2011; revised 17 January 2012; accepted 19 January 2012

Available online 28 January 2012

\begin{abstract}
Open-cell $\mathrm{Zr}_{41.25} \mathrm{Ti}_{13.75} \mathrm{Cu}_{12.5} \mathrm{Ni}_{10} \mathrm{Be}_{22.5}$ bulk metallic glass foams were successfully fabricated by a low-pressure melt infiltration method using crude salts as a space-holder material. Detailed investigations were carried out on the energy absorption property and its underlying mechanism for the present foam. It is found that the foam exhibits high energy absorption capacity and absorbs energy efficiently. Further microscopic observations reveal that the bending of struts, formation and manipulation of multiple shear bands, and microcracking within the material contribute to this foam's energy absorption capability.

(C) 2012 Acta Materialia Inc. Published by Elsevier Ltd. All rights reserved.
\end{abstract}

Keywords: Bulk metallic glass; Foams; Energy absorption; Shear bands

Metallic foams exhibit a unique combination of mechanical, physical and chemical properties, such as high density-compensated strength, good energy absorption capability and excellent acoustic damping, making them very attractive both for structural and functional applications [1-3]. Bulk metallic glasses (BMGs), the parent materials of these foams, have attracted much interest due to their ultrahigh strength, exceptional elasticity, good wear and excellent corrosion resistance, and in particular their low processing temperatures [4-8]. Since the first successful synthesis of BMG foam in the $\mathrm{Pd}-\mathrm{Ni}-\mathrm{Cu}-\mathrm{P}$ system [9], a number of $\mathrm{BMG}$ foam systems have been obtained to date [10-12]. It has been found that impregnating BMG with pores can effectively alleviate their inherently brittle nature and yet retain a considerable fraction of their outstanding strength $[13,14]$. Furthermore, BMG foams exhibit excellent energy absorption capability due to their high compressive ductility combined with moderate strength. Although some efforts have been made to study their mechanical properties, the underlying energy absorption mechanism of these foams remains unclear.

In this paper, open-cell $\mathrm{Zr}_{41.25} \mathrm{Ti}_{13.75} \mathrm{Cu}_{12.5} \mathrm{Ni}_{10} \mathrm{Be}_{22.5}$ BMG foams were successfully fabricated using a vacuum suction casting technique combined with a lowpressure melt infiltration method. The proposed meth-

\footnotetext{
* Corresponding author; e-mail: 1hdai@lnm.imech.ac.cn
}

od, focusing on intermediate-density low-cost foams, was based on the use of cheap commercial crude salts as space-holder material and simple technology. Compressive tests were performed to examine the deformation behavior and energy absorption capacity and efficiency. Moreover, detailed microstructures of the deformed foam have been studied to explain how dissipation occurs.

Master alloy buttons of $\mathrm{Zr}_{41.25} \mathrm{Ti}_{13.75} \mathrm{Cu}_{12.5} \mathrm{Ni}_{10} \mathrm{Be}_{22.5}$ (Vit1) were prepared by arc-melting the high-purity (R99.5\%) constituent elements several times under a Ti-gettered $\mathrm{Ar}$ atmosphere. Sodium chloride $(\mathrm{NaCl})$ was sieved to $500-1000 \mu \mathrm{m}$ particles, sintered for $2 \mathrm{~h}$ at $873 \mathrm{~K}$, and then cooled to $473 \mathrm{~K}$ followed by pouring into a $\mathrm{Cu}$ mold $8 \mathrm{~mm}$ in diameter. Charges of Vit1 buttons were then melted and pressure infiltrated $(70 \mathrm{kPa}$ positive pressure) into the $\mathrm{Cu}$ mold under high-purity Ar gas. After complete solidification and cooling, the Vit1/NaCl composites were machined to cylindrical compression test specimens $8 \mathrm{~mm}$ in diameter using a diamond wafering saw. The salt particles were finally dissolved by immersion in distilled water. The amorphous phase nature of the foam samples was analyzed using X-ray diffraction (XRD) with $\mathrm{Cu} K$ radiation (M18AHF). Quasi-static compression tests were performed with an MTS-810 material testing machine at a strain rate of $5.0 \times 10^{-4} \mathrm{~s}^{-1}$.

Figure 1 shows the XRD pattern and the morphology image (inset) of the Vit1 BMG foam with a diameter of 


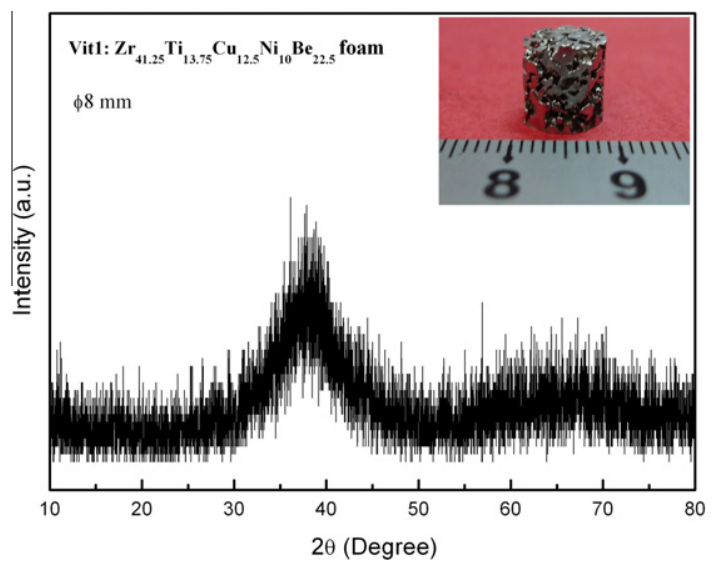

Figure 1. X-ray diffraction pattern of the Vit1 BMG foam $(8 \mathrm{~mm}$ diameter). Inset shows a photograph of the sample.

$8 \mathrm{~mm}$ and porosity of $65 \%$, which verifies the amorphous structure of the present Vit1 foam.

The quasi-static compressive stress-strain curve of the Vit1 foam is shown in Figure 2a. Macroscopically, a stress plateau (collapse stress $\sigma_{p}$, average $30 \mathrm{MPa}$ ) with numerous flow serrations can be clearly observed, followed by the initial elastic response to strain. Beyond the deformation "plateau", the stress rises steeply as the strain reached about $45 \%$, indicating the occurrence of densification. It should be noted that the serrations of BMG foam are of the order of $100 \mu \mathrm{m}$ in size and the stress drop $\left(\Delta \sigma_{p}\right)$ is on average about $16 \mathrm{MPa}$ in the recipient plasticity stage. Similar flow serration phenomena were also observed in monolithic BMGs, which can be attributed to the stick-slip behavior of individual shear bands [15-18]. For the present Vit1 BMG foam, however, it could be considered that the struts of the foam could bear much higher stress as the compression proceeded until some of the struts were crushed, followed by elastic unloading and stress redistribution (corresponding to the stress drop in the stress-strain curve), and then by stop-and-go sliding cycles. The stress-strain curve of Al foams [19] with similar porosity is also given in Figure 2a as a comparison. It should be noted that the flow stress of the Al foam increases smoothly with plastic strain after yielding, differing from the serrated flow of the Vit1 foam. This implies a different deformation mechanism. As is known, the struts of $\mathrm{Al}$ foam remain ductile under loading [1]. However, for Vit1 foams, it can be speculated from the serration flow that the struts reflect the brittle failure which results in stress drop and subsequently stress redistribution among neighboring struts. Based on the obtained stress-strain curve, we can further examine the energy absorption property of the Vit1 foam. Again, Al foam is used for comparison. Figure $2 \mathrm{~b}$ presents the results of the energy absorption capacity of the two foams. Here, the energy absorption capacity $W$, defined as the energy per unit volume necessary to deform a given foam material specimen up to a specific strain $\epsilon_{i}$, can be calculated by [1]:

$W=\int_{0}^{\epsilon_{i}} \sigma d \epsilon$,

where $\sigma$ is the stress at $\epsilon_{i}$. Clearly, the energy absorption capacity of $\mathrm{BMG}$ foam is higher than that of $\mathrm{Al}$
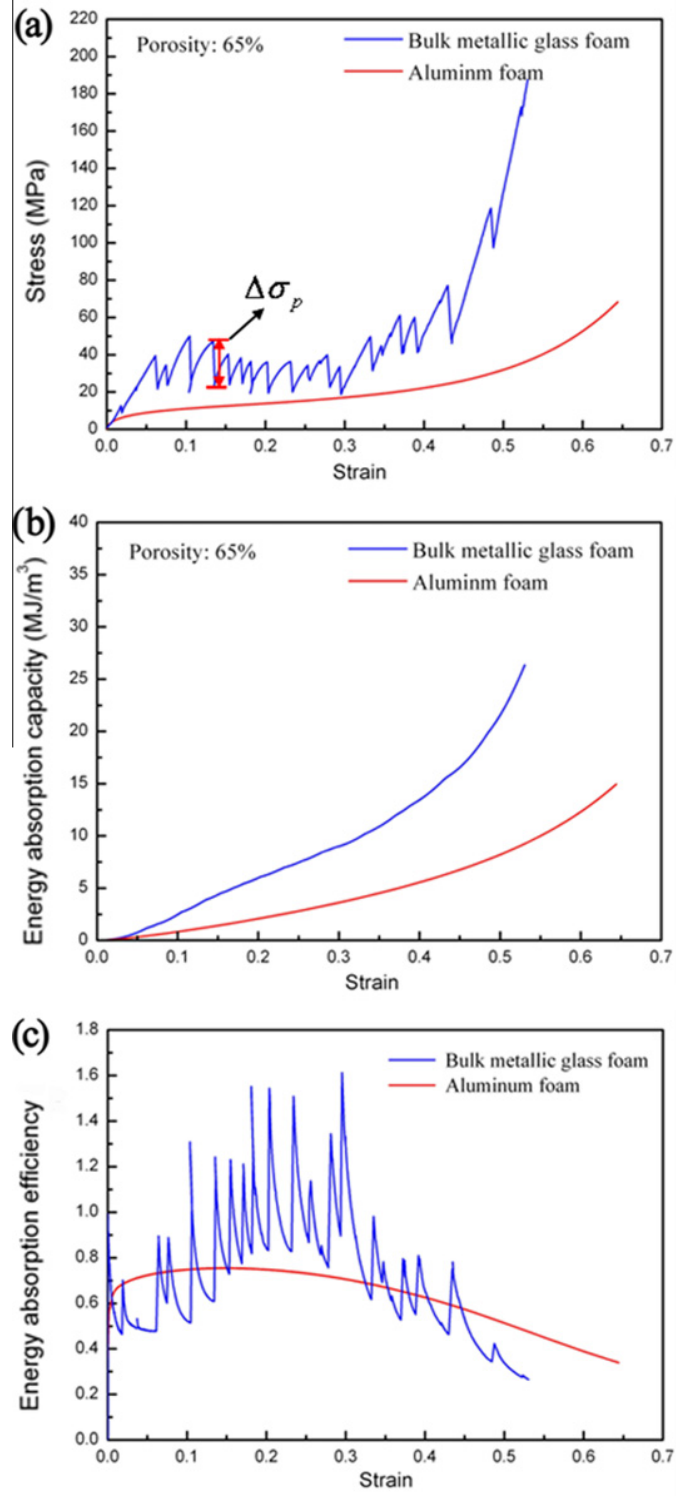

Figure 2. (a) The stress-strain curves of Vit1 BMG foam and the $\mathrm{Al}$ foam; the corresponding energy absorption (b) capacity; and (c) efficiency.

throughout the loading history. Further, we give the energy absorption efficiency of the two foams, as shown in Figure 2c. The energy absorption efficiency, $\eta$, which is the ratio of the real energy absorbed by the material to the ideal energy absorbed for a given strain, $\epsilon_{i}$, is given by [3]:

$\eta=\frac{\int_{0}^{\epsilon_{i}} \sigma d \epsilon}{\sigma_{i} \epsilon_{i}}$

where $\sigma_{i}$ is the stress at $\epsilon_{i}$. The stress-strain curve of an ideal energy absorber is rectangular in shape, with an area defined by the maximum stress $\left(\sigma_{i}\right)$ and strain $\left(\epsilon_{i}\right)$ value. The curve shows that the efficiency of the BMG foam can be enhanced to a maximum value of $160 \%$ at a strain of 0.29 , and maintains a level of not less than $100 \%$ for strains ranging from 0.1 to 0.3 , which corresponds to a relatively stable stress plateau (see Fig. 2c). Moreover, it is obvious that the efficiency of BMG foam is much higher than that of $\mathrm{Al}$ foam at 
medium strains between 0.06 and 0.45 ; this indicates the strain range where optimum energy absorption can usually be obtained.

In fact, a number of mechanisms contribute to energy absorption in cellular solids $[1,3]$. Some are related to the elastic, plastic or brittle deformation of cell walls; others to the friction between the collapsed cell walls and the creation of surfaces. The relevant mechanisms for a particular foam depend on the behavior of the cell wall material and the structure of the cells. However, the question remains: what is the mechanism underlying the better energy absorption property of BMG foams? Among the factors that affect the energy absorption capacity of foams, the collapse stress is very important. It is known that, at the same strain level, a relatively higher collapse stress implies better energy absorption capacity [1]. In the present work, the BMG foam can withstand higher collapse stress than the Al alloy foam, which can be understood from the following equation [2]:

$\frac{\sigma_{p l}^{*}}{\sigma_{y s}}=C_{E}^{\frac{1+x}{2}} \rho_{r e l}^{\frac{3+x}{2}}$,

where $\sigma_{p l}^{*}$ is the collapse stress, $\sigma_{y s}$ is the yield stress of matrix, $C_{E}$ is a constant, $\mathrm{n}$ is a constant related to strain hardening, and $\rho_{\text {rel }}$ is the relative density of the foam. The difference in yield stress between Vit1 BMGs and Al alloys is rather remarkable $[4,20,21]$. However, the terms on the right-hand side of Eq. (3) show little discrepancy between the $\mathrm{Zr}$-based BMG foam and the Al alloy foam $[2,14]$. Therefore, based on Eq. (3), the collapse stress of the two foams is mainly dominated by the yield stresses of their respective matrices. As a consequence, a relatively high energy absorption capacity of foam with nearly the same relative density can be obtained by improving the strength of the solid material. Another factor contributing to the energy absorption capability is the excellent ductility of the foam. To investigate the underlying reasons for the excellent ductility and good energy absorption capability of the BMG foam, the deformation morphologies of struts were characterized using SEM analysis, as shown in Figure 3 . Figure 3 a shows a surface image of the deformed strut with bifurcated and wavy shear bands, features that are generally considered to be the typical for the bending of BMGs of small size [22]. Ring-shaped shear bands are observed in the strut, as shown in Figure 3b. These types of morphology can also be found in the nanoindentation of BMGs [23], indicating the friction between the cell walls occurred when they connected to each other. Figure $3 \mathrm{c}$ shows the intersected and branched shear bands on the strut. The shear bands intersected with each other on the strut surface, which is similar to what was observed on the surface of BMGs after compression testing [24]. Detail corresponding to the branched shear bands (red circle in Fig. 3c) is shown in Figure 3d. One can see that microscale cracks have formed on the boundary of the almost parallel shear bands. Figure $3 \mathrm{e}$ and $\mathrm{f}$ show high-magnification images of the red rectangle in Figure $3 \mathrm{~d}$ and the blue rectangle of Figure 3c, respectively. The enlarged micrographs reveal that two periodic striations with average spacing (micron scale) clearly appear on the surface of shear band offset, similar to the stick-slip
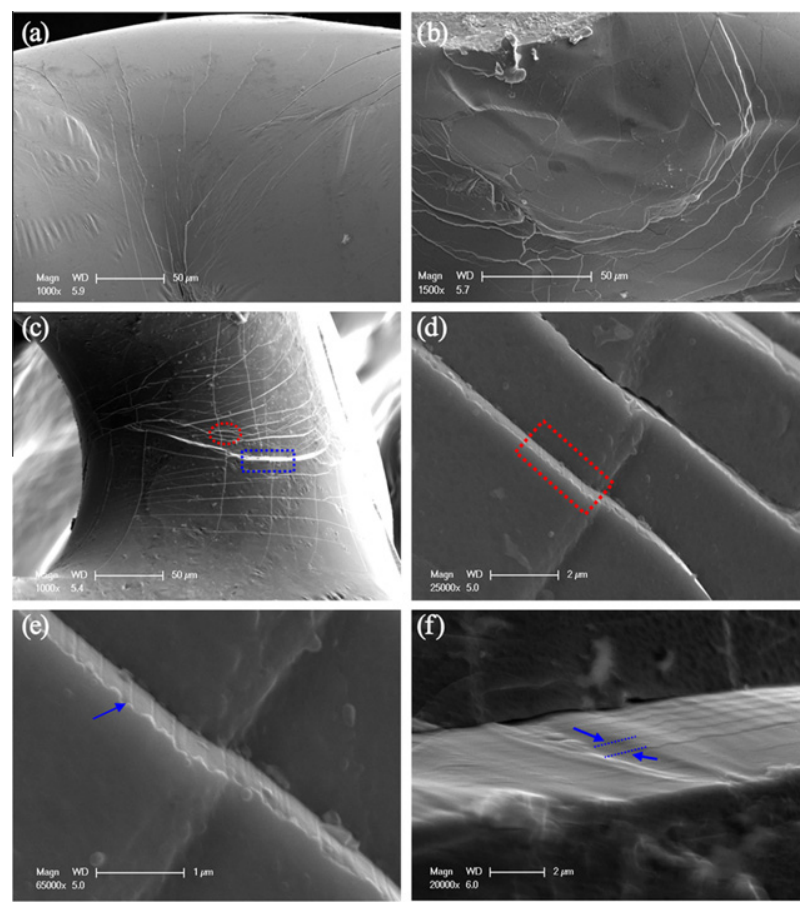

Figure 3. The microstructures of the strut surfaces in the deformed Vit1 BMG foam. SEM observation of (a) strut showing bifurcated and wavy shear bands, (b) strut showing ring-shaped primary shear bands, (c) side view of strut showing multiple shear bands; (d)-(f) detailed corresponding to areas circled in (c), (d) shear band offset and microscale cracks; $(e, f)$ flow striations on the surface of the shear band offset.

striations in the compressed millimeter-scale BMGs, which is caused by the formation and propagation of the shear band [15-17]. The two periodic striations occurred along different directions on the shear band offset (arrowed in Fig. 3e and f), indicating the strut is in a state of multiple stresses. Compared with the deformed struts of Al foam [25], the deformed struts of BMG foam exhibit much more abundant and complicated shear bands, indicating that more energy will be dissipated. The formation of multiple shear bands contributed to the ductility of the struts, which can be explained by the so-called size effect. Significant plasticity/bending ductility can be achieved if the sample size is below a critical size $[8,26-28]$. Here, the size of the struts of the cellular structures in samples should play an important role. In our current work, the characteristic size of the struts is of the order of hundreds of microns, as shown in the inset of Figure 1 and in Figure 3c. According to Refs. $[4,28]$, there exists a critical size of about $1 \mathrm{~mm}$ for Vit 1 BMGs below which the samples can show significant ductility via multiplication of shear bands. These shear bands will further contribute to the macroscopic ductility of the sample. Moreover, it could be deduced form the luxuriant morphologies of the strut surface that the multiple shear bands, microscale cracks, and secondary periodic striations all contribute to the high energy absorption capability.

Figure 4 shows the fracture features of the strut near the node. Detailed morphologies of Figure 4a are magnified in Figure $4 \mathrm{~b}-\mathrm{d}$. Tree-like microscale vein patterns (Fig. 4b) were observed all over the fracture surface; 

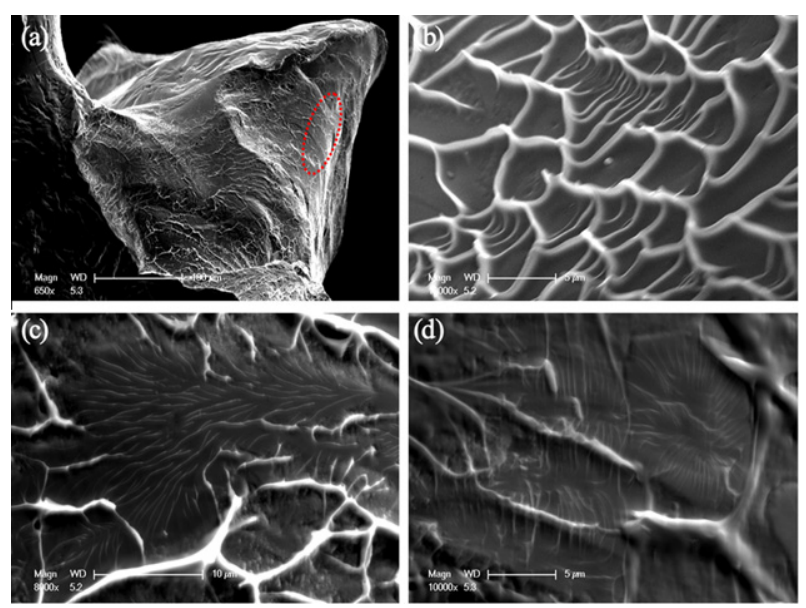

Figure 4. The fracture morphologies of the deformed Vit1 BMG foam: (a) overview of the fracture surface with regions of different morphologies; (b) tree-like vein pattern; (c) round core pattern (detail corresponding to the area circled in (a)); (d) river-like pattern.

these resemble the fracture characteristic of the compressive behavior in monolithic BMGs and these patterns are the evidence of a typical shear fracture mode [20,29-31]. Round core and river pattern (Fig. 4c and d) are presented on the intermediate zone (red circle of Fig. 4a), which are similar to the observations for BMGs under tensile deformation [22,32]. These fracture patterns imply that the material undergoes a rather complex stress state and the struts fracture plastically, but the foam keeps deforming continually and exhibits ductility macroscopically due to the cellular structure, and thus stress oscillation preceded the final densification, resulting in the flow serrations in the stress-strain curve.

In summary, open-cell Vit1 BMG foams were successfully fabricated and they exhibit good energy absorption capability. The results suggested that the excellent property can be attributed to the multiplication of various types of shear bands and resultant ductile cracking in struts experiencing a rather complex stress state due to the presence of pores in the foams.

Financial support is from the NSFC (Grants Nos. 11132011, 11002144 and 11021262), the National Natural Science Foundation of China-NSAF (Grant No. 10976100), the National Key Basic Research Program of China (Grant Nos. 2012CB937500, 2009CB724401) and the Postdoctoral Sustenance Fund of China (Grant No. 20100480483).

[1] L.J. Gibson, M.F. Ashby, Celluar Solids: Structure and Properties, 2nd edn., Cambridge Univsity Press, Cambridge, 1997.
[2] E. Amsterdam, J.Th.M. De Hosson, P.R. Onck, Scripta Mater. 59 (2008) 653.

[3] H.P. Degischer, B. Kriszt, Handbook of Celluar Metals, Wiley-VCH, Weinheim, 2002.

[4] M.F. Ashby, A.L. Greer, Scripta Mater. 54 (2006) 321.

[5] A.H. Brothers, D.C. Dunand, Adv. Mater. 17 (2005) 484.

[6] O.V. Kuzmin, Y.T. Pei, J.T.M. De Hosson, Appl. Phys. Lett. 98 (2011) 233104.

[7] Z.D. Zhu, P. Jia, J. Xu, Scripta Mater. 64 (2011) 785.

[8] J.R. Greer, J.Th.M. De Hosson, Prog. Mater. Sci. 56 (2011) 654

[9] J. Schroers, C. Veazey, W.L. Johnson, Appl. Phys. Lett. 82 (2003) 370

[10] T. Wada, A. Inoue, Mater. Trans. 45 (2004) 2761.

[11] A.H. Brothers, R. Scheunemann, J.D. DeFouw, D.C. Dunand, Scripta Mater. 5 (2005) 335.

[12] M.D. Demetriou, G. Duan, C. Veazey, K.D. Blauwe, W.L. Johnson, Scripta Mater. 57 (2007) 9.

[13] M.D. Demetriou, G. Duan, C. Veazey, J.S. Harmon, J.P. Schramm, W.L. Johnson, Phys. Rev. Lett. 101 (2008) 145702.

[14] A.H. Brothers, D.C. Dunand, Acta Mater. 53 (2005) 4427.

[15] Y.Q. Cheng, Z. Han, Y. Li, E. Ma, Phys. Rev. B 80 (2009) 134115.

[16] S.X. Song, T.G. Nieh, Intermetallics 19 (2011) 1968.

[17] B.A. Sun, H.B. Yu, W. Jiao, H.Y. Bai, D.Q. Zhao, W.H. Wang, Phys. Rev. Lett. 105 (2010) 035501.

[18] D. Klaumünzer, A. Lazarev, R. Maaß, F.H. Dalla Torre, A. Vinogradov, J.F. Loffler, Phys. Rev. Lett. 107 (2011) 185502.

[19] Y.J. Li, F.S. Han, X.F. Wang, X.F. Wang, Y.L. Ren, China Patent, 201110060862.X.

[20] M.Q. Jiang, Z. Ling, J.X. Meng, L.H. Dai, Philos. Mag. 88 (2008) 407.

[21] E. Amsterdam, J.H.B. de Vries, J.Th.M. De Hosson, P.R. Onck, Acta Mater. 56 (2008) 609.

[22] R.D. Conner, Y. Li, W.D. Nix, W.L. Johnson, Acta Mater. 52 (2004) 2429.

[23] Y.F. Gao, B. Yang, T.G. Nieh, Acta Mater. 55 (2007) 2319.

[24] L.H. Dai, Y.L. Bai, Int. J. Impact Eng. 35 (2008) 704.

[25] E. Amsterdam, P.R. Onck, J.Th.M. De Hosson, J. Mater. Sci. 40 (2005) 5813.

[26] O.V. Kuzmin, Y.T. Pei, C.Q. Chen, J.T.M. De Hosson, Acta Mater. 60 (2012) 889.

[27] C.Q. Chen, Y.T. Pei, J.T.M. De Hosson, Acta Mater. 58 (2010) 189.

[28] R.D. Conner, W.L. Johnson, N.E. Paton, W.D. Nix, J. Appl. Phys. 94 (2003) 904.

[29] S. Nowak, A. Pasko, S. Guérin, Y. Champion, Strength Mater. 40 (2008) 154.

[30] M. Martin, L. Kecskes, N.N. Thadhani, Scripta Mater. 59 (2008) 688.

[31] F. Spaepen, Acta Metall. 23 (1975) 615.

[32] D.T.A. Matthews, V. Ocelík, P.M. Bronsveld, J.Th.M. De Hosson, Acta Mater. 56 (2008) 1762. 